\title{
Reply to Fluegge: Association Between Atopic Dermatitis and Autism Spectrum Disorders: A Systematic Review
}

\author{
Lucia Billeci $^{1,2} \cdot$ Alessandro Tonacci $^{2} \cdot$ Gennaro Tartarisco $^{3} \cdot$ Liliana Ruta $^{4,2}$. \\ Giovanni Pioggia ${ }^{3} \cdot$ Sebastiano Gangemi ${ }^{5}$
}

Published online: 29 February 2016

(c) Springer International Publishing Switzerland 2016

We would like to thank Dr Fluegge [1] for his interest and comments on our recently published systematic review [2], which investigates the association between autism spectrum disorders (ASD) and atopic dermatitis (AD).

Dr Fluegge suggests that a possible explanation for the relationship between ASD and AD could be the complex interaction between an enhanced opioidergic activity and reduced baseline vitamin $\mathrm{D}$ levels, both determined by a gestational exposure to nitrous oxide $\left(\mathrm{N}_{2} \mathrm{O}\right)$ [1].

ASD is a complex heterogeneous disorder, the etiology of which seems to be determined by genetic susceptibility, immunological alterations, and likely environmental factors [3]. Indeed, the role of environmental exposure in ASD etiology has been repeatedly suggested [4]. Nitrogen oxides (NOx), consisting of nitric oxide (NO), nitrogen dioxide $\left(\mathrm{NO}_{2}\right)$ and $\mathrm{N}_{2} \mathrm{O}$, are among the compounds that are

Giovanni Pioggia

giovanni.pioggia@cnr.it

1 Department of Clinical and Experimental Medicine, University of Pisa, via Savi 10, 56126 Pisa, Italy

2 Institute of Clinical Physiology, National Research Council of Italy (CNR), via Moruzzi 1, 56124 Pisa, Italy

3 Institute of Applied Sciences and Intelligent Systems "Eduardo Caianiello" (ISASI), National Research Council of Italy (CNR), via Torre Bianca, Mortelle, 98164 Messina, Italy

4 Department of Developmental Neuroscience, Stella Maris Scientific Institute, viale del Tirreno 331, 56018 Pisa, Calambrone, Italy

5 School and Division of Allergy and Clinical Immunology, Department of Clinical and Experimental Medicine, University Hospital "G. Martino", via C. Valeria 1, 98125 Messina, Italy emitted in the environment. Their presence in the atmosphere occurs both naturally (i.e., bacterial processes, biological growth and decay) and due to man's activities (i.e., fossil fuels).

NO is one of the biomarkers of oxidative stress, which has in turn been investigated as a possible mechanism explaining ASD pathogenesis [5]. Oxidative stress may act as a result of the cumulative influence of toxic environmental factors, which could lead to neuronal damage in genetically predisposed individuals [5]. NO is involved in many neuropsychiatric disorders and is known to affect neurodevelopmental processes in the central nervous system [6]. Indeed, elevated NO plasma levels have been found in subjects with ASD compared with control groups [7]. In addition, a positive correlation between ASD and perinatal exposure to air pollution, in particular $\mathrm{NO}$ and $\mathrm{NO}_{2}$, has been found [8].

Since both high plasma ammonia and high plasma NO have been observed in subjects with ASD [6, 7], elevated levels of $\mathrm{N}_{2} \mathrm{O}$ might also be hypothesized. It has been suggested that high amounts of $\mathrm{N}_{2} \mathrm{O}$ could explain the observation of uncontrollable laughter and high pain tolerances seen in some subjects with ASD [9]. However, to the best of our knowledge, until now there has been no study evaluating the $\mathrm{N}_{2} \mathrm{O}$ level in subjects with ASD and correlating it with ASD symptoms.

It could be hypothesized, as Dr Fluegge suggested, that $\mathrm{N}_{2} \mathrm{O}$ could mediate vitamin $\mathrm{D}$ reduction in ASD. It has been suggested, for example, that $\mathrm{N}_{2} \mathrm{O}$ could reduce solar radiation, therefore having an adverse effect by reducing vitamin $\mathrm{D}$ synthesis by the mother and thereby vitamin $\mathrm{D}$ insufficiency in the neonate, leading to susceptibility to respiratory infection and other conditions [10]. Our review on the association between ASD and vitamin D [11] has 
suggested a putative role of vitamin D in the etiology of ASD, at least in a subgroup of subjects.

However, it is worth mentioning that none of the studies that we have analyzed in our systematic reviews on $\mathrm{AD}$ [2] and vitamin $\mathrm{D}$ [11] have evaluated $\mathrm{N}_{2} \mathrm{O}$ in the association among $\mathrm{AD}$, vitamin $\mathrm{D}$, and $\mathrm{ASD}$. Therefore, further studies need to be performed to elucidate the possible role of $\mathrm{N}_{2} \mathrm{O}$ in the interaction between vitamin $\mathrm{D}$ and $\mathrm{AD}$, and in the etiology of ASD.

Moreover, the toxicity of $\mathrm{N}_{2} \mathrm{O}$ has been assessed in healthy individuals and is still controversial [12], although it seems that it could cause adverse effects in certain vulnerable populations. Finally, further studies are needed to elucidate the possible use of opioid antagonists for ASD treatment since they could improve hyperactivity and restlessness without having an impact on core features of ASD in the majority of the participants [13].

In conclusion, in our opinion it is important to bear in mind that ASD is an heterogeneous disorder and that its etiology is multifactorial, so $\mathrm{N}_{2} \mathrm{O}$ exposure might be one of the putative factors contributing to the pathogenesis of ASD, particularly in a subset of genetically susceptible individuals. Furthermore, the use of opioid antagonists and similar medications for ASD treatment should be considered with caution in a subgroup of individuals with specific characteristics.

\section{Compliance with Ethical Standards}

Funding No funding was received for the preparation of this letter.

Conflict of interest Lucia Billeci, Alessandro Tonacci, Gennaro Tartarisco, Liliana Ruta, Giovanni Pioggia, and Sebastiano Gangemi declare that they have no conflicts of interest.

\section{References}

1. Fluegge K. Comment on: "Association between atopic dermatitis and autism spectrum disorders: a systematic review". Am J Clin Dermatol. 2016. doi:10.1007/s40257-016-0180-x.
2. Billeci L, Tonacci A, Tartarisco G, Ruta L, Pioggia G, Gangemi $\mathrm{S}$. Association between atopic dermatitis and autism spectrum disorders: a systematic review. Am J Clin Dermatol. 2015;16: 371-88. doi:10.1007/s40257-015-0145-5.

3. Theoharides TC, Kempuraj D, Redwood L. Autism: an emerging neuroimmune disorder in search of therapy. Expert Opin Pharmacother. 2009;10:2127-43. doi:10.1517/14656560903107789.

4. Herbert MR. Contributions of the environment and environmentally vulnerable physiology to autism spectrum disorders. Curr Opin Neurol. 2010;23:103-10. doi:10.1097/WCO.0b013 e328336a01f.

5. Frustaci A, Neri M, Cesario A, Adams JB, Domenici E, Dalla Bernardina B, et al. Oxidative stress-related biomarkers in autism: systematic review and meta-analyses. Free Radic Biol Med. 2012;52:2128-41. doi:10.1016/j.freeradbiomed.2012.03.011.

6. Cohen BI. Gamma-aminobutyric acid (GABA) and methylmalonic acid-the connection with infantile autism. In: Ryaskin OT, editor. Trends in autism research. Hauppauge: Nova Science Publishers, Inc.; 2004. p. 177-86.

7. Sweeten TL, Posey DJ, Shankar S, McDougle CJ. High nitric oxide production in autistic disorder: a possible role for interferon-gamma. Biol Psychiatry. 2004;55:434-7.

8. Becerra TA, Wilhelm M, Olsen J, Cockburn M, Ritz B. Ambient air pollution and autism in Los Angeles county, California. Environ Health Perspect. 2013;121:380-6. doi:10.1289/ehp. 1205827.

9. Cohen BI. Ammonia (NH3), nitric oxide (NO) and nitrous oxide (N2O) - the connection with infantile autism. Autism. 2006;10:221-3.

10. Grimes DS. Vitamin D and cholesterol. The importance of the sun. York: York Publishing Services; 2009.

11. Pioggia G, Tonacci A, Tartarisco G, Billeci L, Muratori F, Ruta L, et al. Autism and lack of D3 vitamin: a systematic review. Res Autism Spectr Disord. 2014;8:1685-98. doi:10.1016/j.rasd.2014. 09.003.

12. Sanders RD, Weimann J, Maze M. Biologic effects of nitrous oxide: a mechanistic and toxicologic review. Anesthesiology. 2008;109:707-22. doi:10.1097/ALN.0b013e3181870a17.

13. Roy A, Roy M, Deb S, Unwin G, Roy A. Are opioid antagonists effective in attenuating the core symptoms of autism spectrum conditions in children: a systematic review. J Intellect Disabil Res. 2015;59:293-306. doi:10.1111/jir.12122. 